\title{
PASANG SURUT GAMBUH PEDUNGAN DI TENGAH LAJU BUDAYA GLOBAL
}

\author{
I Nengah Sarwa dan Wardizal \\ Jurusan Pedalangan, Fakultas Seni Pertunjukan, \\ Institut Seni Indonesia Denpasar, Indonesia.
}

\begin{abstract}
This article tries to discuss and analyze about the reality of global culture and its implication on traditional performance art. The subject matter of this analysis is the Pedungan Gambuh dance drama, a classical performance, previously a court/palace art, which is thought as the source of the Balinese music and dance drama. Data and facts presented here are drawn from our qualitative research entitled Stream of Pedungan Gambuh dance-drama in the surge of Global Culture. Our research suggests that Gambuh as an entertaining art has recently declined in the rapid flow of Global Culture.
\end{abstract}

Keywords: Gambuh Pedungan, budaya global dan infikasinya.

Pulau Bali yang juga dikenal dengan sebutan pulau seribu pura dengan mayoritas penduduknya menganut agama Hindu, merupakan sebuah pulau yang kaya akan aneka ragam seni pertunjukan. Menurut catatan STSI Denpasar, di awal tahun 1984 tercatat 66 jenis kesenian yang berkembang di Bali. Berdasarkan pemetaan kesenian yang dilakukan oleh Universitas Udayana dan STSI Denpasar pada tahun 1992, tercatat adanya 5612 kelompok seni pertunjukan diseluruh Bali. (Bandem, 1996:62). Tidaklah berlebihan, kalau Mantle Hood seorang tokoh ethnomusikologi dunia asal Amerika Serikat menyebut Bali adalah sorga dari dunia seni "paradise in the world of arts" (Soedarsono, 1999:17).

Gambuh merupakan salah satu bentuk seni pertunjukan klasik yang tumbuh dan berkembang di tengah kehidupan sosio-kultural masyarakat Bali dari dahulu sampai sekarang. Gambuh merupakan suatu istilah yang tidak hanya populer di Bali, akan tetapi diberbagai daerah di Indonesia, seperti Jawa, Sunda, Sulawesi, Lombok, Madura dan lain sebagainya. Kata Gambuh tersebut mempunyai pengertian yang berbeda-beda pada setiap daerah. Di Jawa, kata Gambuh dipakai untuk menyebutkan sejenis kidung (vokal) dan juga nama seekor belalang (Bandem, 1983:68-69). Secara etimologi, Gambuh berasal dari kata Gam yang berarti jalan/bergerak dan $b u h=b h u h=$ bhu yang berarti bupati atau raja-raja. Gambuh berarti jalan hidup atau 
hikayat raja-raja (Bandem, 1975:16-17). Secara ontologis dan terminologis banyak pendapat yang bermunculan terkait dengan pengertian kata Gambuh. Menurut I Made Bandem, "Gambuh adalah terlalu kasih kepada orang yang tidak bisa berterima kasih (bahasa Melayu); kulina wis krep nidake (bahasa Jawa); bisul dan tekes (bahasa Sunda); bangsa kledek, sedangkan kledek itu sendiri adalah sebuah tari-tarian rakyat Jawa Tengah yang ditarikan oleh penari-penari wanita. Penari tersebut menyajikan tariannya di jalan-jalan diikuti oleh beberapa pemain musik Jawa." (Bandem, 1975:25-26). Gambuh merupakan drama tari paling tua dan dianggap sebagai sumber drama tari Bali. Gambuh merupakan warisan drama tari yang dipentaskan dalam istana Majapahit tahun 1334 sampai abad ke 16. Setelah berakhirnya masa kejayaan kerajaan Majapahit di pulau Jawa awal abad ke 16, terjadi gelombang perpindahan besar-besaran raja-raja Majapahit ke pulau Bali. Di pulau Bali kebudayaan Hindu berkembang tanpa gangguan sampai Bali ditaklukan oleh Belanda 1906-1908. Sebagai keluarga bangsawan Jawa yang terbuang ke Bali, mereka hidup bersama para pengikutnya. Seluruh unsur kebudayaan Bali mereka masukan ke dalam peninggalan budaya Majapahit termasuk segala aspek kesenian (Bandem, 1996:26-27). Menurut Dibia, drama tari Gambuh adalah suatu drama tari klasik yang berbentuk total teater, dimana didalamnya terpadu dengan baik dan harmonis unsur-unsur tari, tembang/dialog/vokal drama dan sastra (Dibia, 1978:9).

Sebagai salah satu bentuk seni klasik dan tertua di Bali, Gambuh telah mengalami berbagai periode historis, masa populer atau kurang populer. Gambuh pernah mengalami masa-masa kejayaan, ketika ia terlahir sebagai seni istana dan diayomi oleh para raja. Dalam kapasitasnya sebagai seni istana (puri) serta dukungan yang sangat kuat dari raja yang cinta akan perkembangan kebudayaan, Gambuh mengalami perkembangan yang sangat pesat. Gambuh menjadi seni kesayangan seisi puri dan masyarakat sekitarnya. Kondisi ini telah menyebabkan Gambuh tumbuh dan berkembang menjadi teater besar istana pada abad ke-19. Hal ini semakin mendapat legitimasi dimana kebanyakan istana pada abad ke-19 memilki bangsal khusus yang disebut bangsal Gambuh atau bale pegambuhan (Formagia, 2000:21). Dalam realitasnya sekarang, masa-masa kejayaan Gambuh mungkin hanya tinggal kenangan. Kemajuan yang begitu pesat dibidang ilmu pengatahuan dan teknologi (khususnya teknologi informasi) telah membawa dampak yang luar biasa terhadap perubahan sosio-kultural masyarakat. Kesenian Gambuh mulai ditinggalkan, dan pertunjukan Gambuh sepi penonton.

Artikel ini, mencoba mengungkap tentang pasang surut Gambuh Pedungan di tengah laju budaya global (global culture). Secara umum, keadaan dan perkembangan Gambuh Pedungan (Gambuh yang ada di kelurahan Pedungan Kota Denpasar), tidak jauh berbeda dengan Gambuh yang terdapat pada daerah-daerah lainnya di Bali. Secara historis, Gambuh 
Pedungan merupakan seni istana yang erat kaitanya dengan puri Satria dan puri Pemecutan (Formagia,2000:21). Sebagai seni istana (puri), keadaan dan perkembangan Gambuh Pedungan mendapat perlindungan dan pengayoman dari raja. Pada waktu itu, penguasa (raja) masih tertarik melestarikan semua bentuk tradisi teater dan seni daerah. Pada zaman pemerintahan raja-raja di Bali, Gambuh Pedungan sering mengadakan pertunjukan di puri Pemecutan dan puri Satria. Besarnya perhatian raja dan keterkaitan Gambuh dengan istana (puri), khususnya puri Satria dan Pemecutan, telah menyebabkan Gambuh Pedungan tumbuh dan berkembang dan mencapai puncak keemasannya. Kondisi tersebut juga telah melahirkan penari-penari Gambuh handal. Satu di antara penari yang paling terkenal adalah I Gede Geruh (almarhum), yang sangat besar jasa dan kontribusinya terhadap pelestaraian, perkembangan dan keberlanjutan Gambuh Pedungan. Pada masa jayanya Gambuh Pedungan, pekak Geruh memang tidak semasyur sekehe Gambuh desa Batuan, Kabupaten Gianyar. Namun, Gambuh Pedungan yang termasuk dalam kawasan kota Denpasar itu "menyimpan mutiara" yang terpendam di dalamnya, yakni I Gede Geruh. Pada masa mudanya beliau sanggup memerankan semua tokoh yang ada dalam seni Pegambuhan. Atas kemampuannya itu, Geruh diminta oleh masyarakat untuk mengajarkan tari Gambuh sampai ke desa Depeha Buleleng dan desa-desa lainya di Bali. Walaupun pekak Geruh hidup dengan penuh kesederhanaan, mengaku merasa bangga karena banyak anak didiknya menjadi "orang" yang menempati posisi penting serta sukses dalam meniti karir. Beliau mengabdikan diri sepenuhnya dalam dunia seni dan mewariskan keahliannya itu kepada pelajar/mahasiswa di Kokar dan ASTI Denpasar. Penghargaan yang dimiliki antara lain "Kerti Budaya" dari Pemda Badung tahun 1973; Tanda penghargaan sebagai Dosen luar biasa ASTI Denpasar tahun 1979; Piagam Dharma Kusuma Madya dari Pemda Bali tahun 1981; dan Cincin Emas "Ciwa Nata Raja" dari STSI Denpasar tahun 1994.

Pasang surut Gambuh Pedungan sesungguhnya sudah dirasakan semenjak tahun 70-an. Pada saat itu, Gambuh Pedungan mengalami kemunduran sampai pada taraf yang sangat memperihatinkan. Sebagian besar penari dan penabuh Sekaa Gambuh Pedungan telah berusia lanjut. Struktur pertunjukannya dengan komposisi tari dan tabuh yang dulunya lengkap (utuh) sudah tidak lengkap lagi. Instrumen gamelan pengiring tari juga telah banyak yang rusak, sehingga dalam setiap pementasan selalu memakai gamelan yang tidak lengkap (Sudana, 1993:2-3). Dalam perkembangan jaman sekarang ini yang semakin mengglobal Gambuh Pedungan mulai ditinggalkan, dan regenerasi dibidang seni pertunjukan Gambuh dirasakan cukup sulit (Sudiana, 2000:5).

\section{MASA KEEMASAN KESENIAN GAMBUH}


Zaman pemerintahan raja-raja di Bali dapat dicatat sebagai masa keemasan kesenian Bali. Pada zaman pemerintahan raja-raja di Bali, kesenian tradisonal mengalami perkembangan yang sangat pesat. Hal ini tidak terlepas dari perhatian dan rasa cinta para raja terhadap perkembangan kebudayaan. Jatuhnya Majapahit awal abad ke-16, telah mengakibatkan hubungan Jawa dan Bali semakin erat. Pada masa ini banyak orang-orang Jawa yang menetap di Bali serta menurunkan keseniannya dari generasi ke genarasi berikutnya. Sejarah juga mencatat bahwa abad ke-16 dan ke-19 merupakan masa jayanya kerajaan Bali dengan raja-raja seperti Dalem Waturenggong (1460-1550); Dalem Bakung (1550-1580); Dalem Sagening (1580-1665) dan Dalem Dimade (1665-1686) dan seterusnya. Pada masa ini kesenian Bali mencapai puncak keemasanya dengan terciptanya tari-tarian seperti Gambuh, Topeng, Wayang Wong, Parwa, Arja, Legong Keraton dan kesenian klasik lainya ( Bandem, 1985:5-8).

Secara historis, Gambuh merupakan kesenian istana (puri) yang erat kaitanya dengan raja-raja pada zaman dahulu. Hal ini relevan dengan pendapat yang mengatakan, Gambuh adalah drama klasik yang tertua di Bali dengan mengambil lakon dari cerita panji yang menggambarkan keadaan raja atau kerajaan di Jawa (Rota, 1977:1) Sejak zaman dahulu, Gambuh telah menjadi kesenian yang amat dibanggakan oleh kalangan istana (Formagia, 2000:12). Terkait dengan Gambuh Pedungan, keadaan dan perkembanganya tidak jauh berbeda dengan Gambuh yang terdapat pada istana-istana (puri) lainya di Bali. Secara historis, Gambuh Pedungan merupakan seni istana yang erat kaitanya dengan puri Satria dan puri Pemecutan. Sebagai seni istana (puri), keadaan dan perkembangan Gambuh Pedungan mendapat perlindungan dan pengayoman dari raja. Pada waktu itu, penguasa (raja) masih tertarik melestarikan semua bentuk tradisi teater dan seni daerah. Pada zaman pemerintahan raja-raja di Bali, Gambuh Pedungan sering mengadakan pertunjukan di puri Pemecutan dan puri Satria. Besarnya perhatian raja dan keterkaitan Gambuh dengan istana (puri), khususnya puri Satria dan Pemecutan, telah menyebabkan Gambuh Pedungan tumbuh dan berkembang dan mencapai puncak keemasanya. Kondisi tersebut juga telah melahirkan penari-penari Gambuh handal. Satu diantara penari yang paling terkenal adalah I Gede Geruh (almarhum), yang sangat besar jasa dan kontribusinya terhadap pelestaraian, perkembangan dan keberlanjutan Gambuh Pedungan. Dengan semakin memudarnya kekuasaan puri, maka semakin menipis pula keterkaitan Gambuh dengan puri. Dalam situasi yang demikian, Gambuh kemudian menjadi milik kelompok atau banjar yang bersangkutan. Sebagai milik kelompok, Gambuh kemudian memiliki tempat pemujaan di banjar/desa dan pamaksan (Formagia, 1999/2000:34). Pada masa kerajaan, aktivitas seni budaya lebih banyak berpusat di istana (puri). Para seniman mendapat pengayoman dari raja seperti pemberian tanah, pembebasan pajak dan bebas (luput) dari berbagai ayahan desa. Kemudian 
seni budaya tersebut di atas berlangsung sampai masa kolonial. Sesudah masa kemerdekaan mulai muncul berbagai karya seni, tidak lagi hanya berpusat di puri (istana) tapi sudah tumbuh dan berkembang di masyarakat) (Agung, 2000:9).

\section{PASANG SURUT GAMBUH PEDUNGAN DI TENGAH LAJU BUDAYA GLOBAL (GLOBAL CULTURE).}

Secara umum, pasang surut Gambuh Pedungan dapat dilihat secara kuantitatif, maupun kualitatif. Secara kuantitatif hal itu terlihat dari jarangnya Gambuh Pedungan melakukan pementasan, kecuali untuk keperluan upacara di Pura; struktur pertunjukan yang tidak lengkap; sulitnya regenerasi; serta peralatan (terutama instrumen musik) yang sudah tidak lagi lengkap, walaupun masih memadai digunakan untuk mengiringi drama tari Gambuh. Secara kualitatif, masa-masa kejayaan I Gede Geruh (almarhum) sebagai penari yang handal, dan I Made Lemping (almarhum) dibidang musik Gambuh, sudah sangat sulit diraih pada masa sekarang. Di samping proses regenerasi yang kurang mengembirakan, penari maupun penabuh yang ada sekarang hanya pada batas kemampuan sekedar "bisa" membawakan tabuh maupun tari. Tidak seperti I Gede Geruh maupun I Made Lemping yang "mumpuni" dibidang tari maupun tabuh. Secara fungsional, Gambuh Pedungan lebih mempunyai fungsi sebagai pelengkap upacara (piodalan) di pura. Tempat pementasan adalah pura Puseh Pedungan. Walaupun secara sosial politik, kekuasaan raja-raja di Bali sudah berakhir dan istana (puri) tidak lagi menjadi pelindung dan pengayom utama kesenian Gambuh, secara kultural Gambuh Pedungan masih mempunyai hubungan baik dan ikatan bathin dengan puri Satria. Sampai sekarang Gambuh Pedungan masih sering mengadakan pementasan dalam rangka upacara (piodalan) di pura milik puri tersebut.

Di samping fungsi utamanya sebagai seni pelengkap upacara (piodalan) di pura Puseh Pedungan, Gambuh Pedungan juga dapat difungsikan sebagai seni tontonan (art by persentation) untuk acara-acara yang bersifat sosial kemasyarakatan. Pementasan yang pernah dilakukan adalah dalam acara Pesta Kesenian Bali (PKB) yang lebih bersifat insidentil (kalau diundang). Secara reguler, sekaa Gambuh Pedungan juga pernah mengisi acara di hotel Club Met Nusa Dua, Bali dua kali dalam seminggu. Sekarang pementasan di Club Met Nusa Dua tidak lagi dilakukan atas keinginan pihak hotel. Untuk melihat bagaimana responbilitas masyarakat (penonton) untuk menyaksikan pertunjukan Gambuh Pedungan, terutama dalam fungsinya sebagai seni tontonan (art by persentation), pementasan Gambuh Pedungan pada acara Pesta Kesenian Bali dan pementasan di Club Met Nusa Dua Bali cukup relevan dikemukakan dalam tulisan ini. Menurut pengakuan I Nyoman Sudiana (pelatih tabuh sekaa Gambuh Pedungan), 
pementasan sekaa Gambuh Pedungan di acara Pesta Kesenian Bali (PKB) cukup mendapat respon positif dari masyarakat (pengunjung PKB). Namun, jika diukur secara kuantitatif (besarnya jumlah penonton), keadaanya kurang mengembirakan. Hal ini ditandai dengan minimnya penonton yang menyaksikan jalannya pementasan. Bahkan sangat jarang penonton yang menyaksikan pementasan sampai selesai. Hal ini berbeda dengan pementasan yang dilakukan oleh group-group luar negeri yang selalu dipadati oleh banyak penonton (Sudiana, wawancara tangal 5 Agustus 2005).

Kehadiran jumlah penonton dalam menyaksikan sebuah pementasan seni pertunjukan, secara langsung maupun tidak langsung akan membawa implikasi terhadap keberlangsungan hidup sebuah bentuk seni pertunjukan. Mao Tse Tung sebagaimana dikutip Brandon mengatakan, penonton ibarat samudra dan rombongan-rombongan seni pertunjukan adalah ikan yang berenang di dalamnya. Tanpa samodra ikan akan mati, tanpa penonton rombongan (seni pertunjukan) akan mati. Seni pertunjukan dan penonton adalah belahan-belahan yang bergandengan dari situasi seni pertunjukan secara total. Seni pertunjukan merefleksikan penonton dan penonton adalah sejenis sosok kaca dari seni pertunjukan (Brandon, 2003:335).

Berdasarkan fakta sebagaimana diuraikan di atas, dewasa ini Gambuh Pedungan berada dalam masa pasang surut/kemunduran. Masa-masa keemasan ketika zaman pemerintahan raja-raja di Bali dulu terlalu sulit untuk diraih di zaman sekarang. Hal ini cukup relevan dengan apa yang dikemukakan oleh Suartaya, "mengkhawatirkan memang keadaan drama tari yang merupakan induk dari seni pertunjukan Bali dan sebagian musik Bali ini. Ia mungkin merasa bagaikan jompo yang dihempaskan anak cucunya. Mungkin pula ia dianggap bak sumber air yang telah kering. Karena merasa sudah peot, agaknya ia minder bersaing dengan sendra tari yang cantik dan bahenol yang jadi rebutan penonton (Suartaya, 1994:8). Dalam konteks yang lebih luas, dewasa ini kehidupan kesenian Gambuh berada dalam taraf yang kurang mengembirakan. Bali Post, secara khusus pernah memuat sebuah tulisan dengan judul, "Drama Tari Gambuh Mengapa terpuruk". Salah satu bagian dari tulisan tersebut menyebutkan, Drama tari Gambuh merupakan bentuk kesenian yang usianya tergolong tua di Bali. Namun, usia tua tak menjamin kalau kemudian seni klasik tradisional ini menjadi eksis di masyarakat. Gambuh belakangan ini justru mulai mengalami masa surut. Banyak sekaa Gambuh yang mati suri dan bahkan ada yang lenyap tanpa bekas (Bali Post, Minggu 26 Juni 2005:11).

\section{Faktor Penyebab Kemunduran Gambuh Pedungan}

Secara epistemologis, pasang surut Gambuh Pedungan, tidak dapat dilepaskan dari berbagai perubahan (perubahan kebudayaan) yang sekarang ini tengah melanda berbagai negara di dunia termasuk Indonesia, bahkan Bali. Kebudayaan akan selalu berubah (culture is in constant flux), atau 
dengan perkataan lain kebudayaan mengalami transformasi dari masa-ke masa (Soedarsono, 1999:160) Secara umum, perubahan kebudayaan tersebut setidaknya disebabkan oleh dua faktor yaitu faktor lingkungan dan kontak dengan kebudayaan asing. Kemampuan berubah merupakan sifat yang penting dalam kebudayaan manusia. Tanpa itu, kebudayaan tidak akan mampu menyesuaikan diri dengan keadaan yang senantiasa berubah (Haviland, 1988:251). Selanjutnya, Alvin Boskoff dalam Soedarsono mengungkapkan bahwa perubahan sosial budaya dalam masyarakat disebabkan adanya faktor internal dan faktor eksternal. Faktor internal yang dimaksud adalah faktor yang datang dari dalam, sedangkan faktor eksternal merupakan faktor yang datang dari luar (Soedarsono, 1998:2).

Salah satu tonggak sejarah yang sangat berpengaruh terhadap perubahan kebudayaan di tengah kehidupan sosio kultural masyarakat Bali adalah jatuhnya Bali ke tangan Belanda. Secara resmi imprealisme Belanda di Bali diawali dengan peristiwa Puputan Badung pada tahun 1906, kemudian disusul dengan Puputan Klungkung tahun1908 (Bandem, 1985:11) Belanda mengatur kembali sistem administrasi dan membagi kekayaan kerajaan menjadi milik perorangan, keluarga kerajaan dan "negara" (Belanda). Dalam pembagian ini selanjutnya ada pembagian lagi sebagai tunjangan berupa tanah, bagi mereka mereka yang memiliki pertalian sistem tempat pemujaan (pura) dan mereka yang ada hubungan dengan "negara". Kerajaan tidak lagi memiliki kekayaan ataupun posisi untuk menguasai sumber-sumber daya sebagai penunjang dirinya dalam perannya sebagai pusat kesenian, sehingga karya Gambuh mengalami penurunan. Demikian pula halnya dengan hubungan pertalian yang telah lama terjalin dengan kerajaan diatur kembali oleh Belanda. Abdi kerajaan Parekan dipandang sebagai budak yang harus dimerdekakan. Penduduk desa yang mempunyai layanan kepada kerajaan, para pengayah tidak lagi dilihat oleh Belanda memiliki pertalian penting dengan istana (Formagia, 2000:48). Menurut Brandon, salah satu akibat yang paling fatal dari ekspansi Barat di Asia Tenggara (termasuk Indonesia yang dikuasai Belanda) adalah bahwa seni pertunjukan istana merosot dimana-mana. Sebagian kemerosotan disebabkan oleh faktor-faktor ekonomi. Dana istana dikurangi dengan drastis oleh pemerintah kolonial yang baru dan raja-raja lokal serta para pangeran sekonyong-konyong kedapatan tidak memiliki lagi sumber-sumber keuangan untuk menopang hiburan-hiburan istana yang mewah. Minat kepada seni istana dipandang sebagai kolot (Brandon, 2003:54). Di samping itu, jenis kesenian yang berkembang pada zaman kolonial Belanda adalah seni "kemasan" yang diperuntukan sebagai hiburan bagi wisatawan (Kayam, 2000:4-5). Dengan kondisi yang demikian, Gambuh sebagai seni yang dipertontonkan terutama untuk memperteguh wibawa istana atau sistem kekuasaan feodal di istana semakin tidak mendapat tempat. Meletusnya perang Dunia ke II, merupakan pukulan yang "mematikan” bagi Gambuh, 
karena kekuasaan dan wewenang raja maupun puri (istana) yang telah "didegradasi" semenjak pemerintahan Belanda, secara langsung maupun tidak langsungpun telah berakhir.

Tahun 1966 sampai sekarang, merupakan masa kebangkitan kesenian Bali. Di Bali, terdapat beberapa lembaga pemerintah yang aktif berperan serta dalam penggalian, pembinaan dan pelestarian kesenian tradisonal Bali seperti Akademi Seni Tari Indonesia (ASTI) Denpasar, kini menjadi Institut Seni Indonesia (ISI) Denpasar; Sekolah Menengah Karawitan Indonesia (SMKI) Denpasar; Sekolah Menengah Seni Rupa (SMSR) Denpasar. Di samping itu, suatu organisasi masyarakat yang paling berperan dalam pembinaan kesenian di Bali ialah Banjar. Hampir setiap Banjar di Bali memiliki organisasi kesenian yang dinamakan sekaa, seperti sekaa gamelan (organisasi gamelan), sekaa pesantian (organisasi sastra), sekaa kidung (organisasi menembang) dan lain-lain. Awal tahun 1970-an sampai sekarang dapat dicatat sebagai masa kebangkitan seni pertunjukan. Menurut pendataan yang dilakukan oleh Akademi Seni Tari Indonesia (ASTI) Denpasar, pada awal tahun 1984 tercatat sebanyak 66 jenis kesenian dan hampir semuanya masih hidup sampai sekarang (Bandem, 1985:18-23).

Walaupun seni pertunjukan Bali berada dalam masa kebangkitan sebagaimana di kemukakan Badem di atas, secara lebih mendentail dan substansial seni pertunjukan Gambuh Pedungan berada dalam situasi sebaliknya. Secara faktual Gambuh Pedungan memang masih hidup dan eksis sampai sekarang dibawah binaan banjar Puseh dan banjar Manesa Pedungan. Namun, secara kuantitatif dan responbilitas yang diberikan oleh masyarakat, baik dalam menyaksikan pementasan Gambuh maupun dalam mempelajari kesenian Gambuh, Gambuh Pedungan berada dalam taraf yang kurang mengembirakan, kalau tidak bisa disebut memprihatinkan. Gambuh Pedungan, memang telah menjadi bagian dari kurikulum dalam proses belajar mengajar di ASTI/kini ISI Denpasar. Namun, kalaupun ada keberhasilan yang dicapai hanya terletak pada pembelajaran drama tarinya, dimana mahasiswa ISI Denpasar khususnya jurusan tari menguasai dan/atau bisa membawakan drama tari Gambuh Pedungan. Di samping itu, Gambuh Pedungan juga telah menjadi objek kajian (penelitian) dikalangan dosen. Pada sisi lain, khususnya musik Gambuh, situasinya cukup memprihatinkan. Penulis pernah menyebarkan angket (quisioner) kepada mahasiswa Jurusan karawitan STSI Denpasar angkatan tahun 2004/2005, untuk melihat sejauh mana mereka mengetahui dan menguasai teknik permainan gamelan Gambuh, khususnya suling Gambuh yang menjadi identitas dan ciri khas gamelan Gambuh. Hasil yang didapat menunjukkan , dari lebih kurang 100 orang mahasiswa yang diberikan daftar pertanyaan (quisioner), tidak satupun yang bisa dan menguasai teknik permainan suling Gambuh (Wardizal, 2004:25). Penulis juga pernah menyaksikan pementasan drama tari Gambuh Pedungan yang dilakukan oleh mahasiswa jurusan Tari ISI Denpasar dalam 
rangka ujian akhir semester (Juli 2005) dengan penabuh dari semester IV jurusan Karawitan. Sebuah pemandangan yang cukup ironis, dimana gamelan yang dipergunakan sebagai musik iringan bukan gamelan Gambuh melainkan gamelan Semara Pagulingan. Cara seperti ini perlu diminimalisir, apalagi jika dikaitkan dengan misi dan visi STSI/ISI Denpasar sebagai pusat penggalian, pembinaan dan pelestarian kesenian tradisional, khususnya kesenian tradisonal daerah Bali.

Perubahan kebudayaan lain yang terjadi dalam masyarakat Bali dan mempunyai implikasi yang cukup luas terhadap keberlanjutan kehidupan Gambuh adalah, apa yang pernah diutarakan oleh futuris kondang Alfin Toffler tentang perubahan fungsi istana kerajaan pada zaman modern ini. Dalam bukunya Powershife (1990) Toffler mengatakan bahwa istana-istana kerajaan yang dahulu merupakan pusat segala-galanya, sekarang bergeser fungsinya hanya sebagai objek wisata saja. Pergeseran semacam ini jelas disebabkan karena adanya pergeseran kekuasaan. Pada zaman kerajaan, ketika raja yang menggunakan konsep devaraja ( di Asia Tenggara) masih merupakan penguasa dalam segala-galanya. Pada zaman modern ini ia lebih hanya sebagai lambang kebesaran budaya pada masa lalu (Soedarsono, 1999:161). Prediksi Tofler sebagaimana dikutip Soedorsono di atas, menemukan buktinya di Bali dimana puri telah bergeser fungsinya sebagai objek wisata. Bahkan beberapa puri (istana) di Bali mengemas seni pertunjukan wisata (tourist art) yang diperuntukkan sebagai hiburan bagi wisatawan. Puri-puri tersebut diantaranya adalah puri Peliatan, Puri Agung Saren Ubud, dan Puri Kerambitan. Puri Peliatan dari Kabupaten Gianyar dewasa ini setiap malamnya dari jam 19.30 sampai jam 21.00 wita menyajikan kemasan pertnjukan wisata yang diberi judul Tirta Sari Dances and Musician Of Peliatan. Kemasan pertunjukan wisata yang disajikan oleh Puri Agung Saren Ubud ditampilkan oleh group Panca Artha yang diberi judul Gabor Dances. Sedangkan pertunjukan wisata yang disajikan oleh Puri Kerambitan diberi judul Kerambitan Night (Soedarsono, 1999:44-45).

Banyak pemerhati seni budaya yang mengkaitkan kehidupan seni pertunjukan tradisioanal, dengan arus globalisasi atau budaya global (global culture). Dewasa ini, masyarakat dunia dihadapkan kepada perkembangan yang begitu pesat dibidang ilmu pengetahuan dan teknologi. Kemajuan ilmu pengetahuan dan teknologi (khususnya teknologi informasi) secara langsung maupun tidak langsung akan menyebabkan terjadinya perubahan kebudayaan. Teknologi dan budaya merupakan dua hal yang saling mengkait, bahkan terdapat hubungan yang timbal balik. Kemajuan pemikiran manusia dalam bentuk kemajuan kebudayaan mendorong majunya ilmu pengetahuan dan teknologi, dan sebaliknya kemajuan dalam bidang ilmu pengetahuan dan teknologi menjadi pemacu kemajuan kebudayaan (Sumaatmaja, 1998:60). Bagaimanapun juga, kemajuan ilmu pengatahuan dan teknologi cepat atau lambat akan mempengaruhi kaidah- 
kaidah kebudayaan, lembaga-lembaga sosial budaya dan (dari segi sosial politik) pola-pola pengambilan keputusan kebijakan pemerintah (Sudarsono, 1992:4). Sekarang ini, kecepatan dan luas penemuan baru di bidang tekhnologi (termasuk teknologi informasi) telah sedemikian besarnya, dan merupakan sesuatu yang tidak dapat dibendung dan ditolak. Mungkin tidak banyak yang menyadari, bahwa kehadiran televisi telah mengubah perilaku, pola hidup dan komunikasi dalam keluarga. Banyak waktu yang kemudian dihabiskan untuk duduk di depan televisi, sehingga waktu yang tersedia untuk berkomunikasi diantara sesama anggota keluarga akan berkurang. Juga mungkin tidak banyak yang menyadari bahwa kehadiran iklan di media masa terutama televisi, telah memicu liberalisasi dan demokratisasi dalam keluarga. Iklan mengajari orang untuk memilih segala hal yang sesuai dengan kebutuhan hidupnya. Internalisasi dari pola pikir yang demikian selanjutnya akan diterapkan juga dalam kehidupan lainya, termasuk dalam memenuhi kebutuhan akan seni atau keindahan. Telekomunikasi juga telah mengubah pola hubungan diantara manusia. Orang tidak perlu bertatap muka untuk dapat berkomunikasi antar mereka. Disinipun muncul elemen yang secara berangsur akan mengikis budaya feodal dan budaya paternalisme. Disisi lain, telekomunikasi akan mendekatkan hubungan antara sesama manusia secara gobal (Supardan, 1991:11-12). Dalam kemajuan abad ke-21 ini, teknologi cenderung tampil sebagai kekuatan yang otonom terhadap manusia. Dengan demikian, teknologi disatu pihak mempunyai kekuatan manulatif terhadap alam dan kebutuhan manusia, dan dilain pihak mampu menggeser hubungan sosial dan kedudukan manusia itu sendiri. Kekuatan itu mampu menjangkau manusia secara ekstensif dan mengubah pola budayanya secara intensif (Poespowardojo, 1993:70).

Kondisi pertunjukan Gambuh, bahkan seni pertunjukan Bali dalam konteks yang lebih luas juga dihadapkan pada berbagai perubahan dan dinamika yang terjadi ditengah kehidupan masyarakat. I Wayan Dibia mengemukakan:

Didalam kurun waktu dua puluh lima tahun terakhir ini telah terjadi pergeseran muatan dramatik (change of dramatic content) dalam seni pertunjukan Bali. Walaupun muatan artistiknya, nilai pendidikannya, kritik sosialnya dan pesan-pesan penerangannya masih tetap ada, muatan seni pertunjukan Bali dewasa ini semakin didominir oleh unsurunsur hiburan berupa adegan-adegan kocak yang menimbulkan gelak tawa penonton. Lelucon, bebanyolan atau babagrigan, tampaknya telah menjadi suatu senjata handalan seniman pentas untuk menahan penonton. Tujuan dari pagelaran kesenian, di samping selain mendidik, memberi penerangan, dll, membuat penonton tertawa (to amuse) nampaknya akhir-akhir ini semakin diutamakan. Ada kesan, yang terpenting bagi para seniman pertunjukan saat ini adalah membuat suasana "geer" (Dibia, 1995:51) 
Terjadinya pergeseran selera artistik penonton (dari wacak ke kocak meminjam istilahnya Dibia) telah membawa dampak yang kurang menguntungkan terhadap pertunjukan Gambuh. Hal ini disebabkan Gambuh dapat digolongkan ke dalam jenis tontonan serius. Untuk bisa menikmati dan memahami kesenian Gambuh, diperlukan keseriusan dan daya apresiasi dari para penonton. "Sebagai ekspresi budaya Gambuh memang berasal dari tata perilaku yang penuh aturan rumit, tatanan puri. Karena itu, bobot artistik dari Gambuh mencuat dari kompleksitasnya, baik koreografinya maupun komposisi musiknya" (Suartaya, 1994:8). Di samping itu, tema cerita yang diangkat lebih banyak mengisahkan kehidupan para raja. Hal ini sesungguhnya tidak terlepas dari latar belakang kesenian Gambuh yang nota bene adalah mantan kesenian istana. Terkait dengan hal ini, Bandem mengemukakan, "Sebagai suatu bentuk drama tari tertua di Bali, Gambuh mengambil lakon dari cerita panji, sebuah hikayat yang mengisahkan kehidupan, peperangan, roman dari raja-raja dan kaum bangsawan di Jenggala, Kediri, Gegelang dan sebagainya. Di Bali, cerita panji ini dikenal dengan nama Malat dengan Panji Inu Kertapati sebagai tokoh utama" ( Bandem, 1983:68-70). Dengan kondisi yang demikian, Unsur "menghibur" yang mampu membuat penonton tertawa, sehingga merasa betah dalam menyaksikan jalannya pertunjukan (sebagaimana kecenderungan seni pertunjukan Bali dewasa ini) agak sulit ditemukan dalam pertunjukan Gambuh. Hal ini diakui oleh Dibia bahwa, sajian dramatik yang terlalu serius nampaknya kurang mendapat pasaran (Dibia, 1995:62) Sejalan dengan pendapat Dibia, Brandon mengatakan, menghadiri seni pertunjukan adalah hiburan santai dan informal bagi penonton di Asia Tenggara. Orangorang datang ke gedung (tempat pertunjukan) pada malam hari untuk melihat apakah yang sedang bermain. Bila senang lakon itu, mereka lalu memutuskan untuk menyaksikannya di sana (Brandon, 2003:341).

Faktor lain yang disinyalir sebagai penyebab kemunduran kesenian Gambuh adalah karena sulit dan tiadanya regenerasi sehingga pergantian penari maupun penabuh tidak bisa dilaksanakan. Konon keterpurukan Gambuh dibeberapa tempat disebabkan enggannya generasi muda belajar Gambuh. Di banyak tempat, sudah menjadi rahasia umum kalau generasi muda malas belajar Gambuh. Mereka mengaku mengalami kesulitan, karena untuk dapat menari Gambuh secara baik dasarnya adalah bakat. Ada anggapan dikalangan generasi muda bahwa gerakan-gerakan tari Gambuh sangat rumit dan "menyebalkan". Di samping itu, dalam Gambuh bukan hanya gerakan tari saja yang ditampilkan, juga ada dialog-dialog yang harus diucapkan dalam bahasa Jawa kuno atau bahasa kawi. Konon hal yang satu ini menjadi salah satu faktor penyebab mengapa anak muda kini enggan mempelajari Gambuh. Kebanyakan sekaa Gambuh yang masih aktif dewasa ini semata-mata karena senimannya menaruh rasa peduli yang sangat tinggi 
pada warisan leluhurnya. Keberadaan mereka lebih banyak karena adanya keterkaitan antara seniman Gambuh dengan sesuhunan-nya di Pura.

\section{SIMPULAN}

Mencermati pasang surut Gambuh Pedungan di tengah laju budaya global (global culture), sudah saatnya Pemerintah Daerah Tingkat I Bali yang secara tidak langsung berfungsi sebagai maesenas, pelindung dan pengayom berbagai kekayaan seni budaya Bali untuk lebih pro aktif memainkan peranannya dalam menjaga kelestarian kesenian tradisional, khususnya kesenian klasik seperti Gambuh Pedungan. Tanpa adanya perhatian dari pemerintah, Gambuh (khususnya Gambuh Pedungan) akan sulit berkembang. Di samping itu, ISI Denpasar sebagai satu-satunya lembaga pendidikan tinggi kesenian di Bali, secara langsung maupun tidak langsung memiliki tanggung jawab moral terhadap pelestarian dan kesinambungan kesenian Gambuh (Gambuh Pedungan). Apalagi Gambuh Pedungan sudah sejak lama menjadi bagian dari kurikulum sebagai proses pembelajaran kepada mahasiswa, bahkan ketika lembaga ini masih bernama Akademi Seni Tari Indonesia (ASTI). Di pundak lembaga ini sesungguhnya juga terpikul tanggung jawab tentang alih generasi dibidang pegambuhan. Kepada generasi muda (teruna-teruni) desa Pedungan sebagai pemegang estafet utama kesenian Gambuh, motivasi dan kepeduliannya untuk mempelajari kesenian Gambuh sangat diharapkan. Kalau tidak demikian, Gambuh Pedungan yang selama ini menjadi identitas, jati diri dan kebanggaan masyarakat Pedungan akan bisa hilang di telan jaman yang selalu berubah.

\section{DAFTAR RUJUKAN}

Agung, Putra. 2000. "Dinamika Seni Budaya Bali Memasuki Abad ke-21" Makalah, disampaikan dalam Seminar Regional dalam Rangka Dies Natalis XXXIII dan Wisuda XII STSI Denpasar tgl 18 Januari 2000. Denpasar: ISI.

Ardika, I Wayan. 1999. “Warisan Budaya dan Globalisasi”. Makalah, disampaikan pada Matrikulasi Program Magister (S-2) Kajian Budaya Universitas Udayana tgl 13 Juli 1999. Denpasar: Unud

Bali Post, Minggu Wage 26 Juni 2005

Bandem, I Made. 1975. Panitithalaning Pegambuhan. Denpasar: Proyek Percetakan/ Penerbitan Naskah-Naskah Seni Budaya. 1983. Ensiklopedi Tari Bali. Denpasar: ASTI.

1985. Keadaan dan Perkembangan Kesenian Bali Tradisional Masa Kini. Denpasar: ASTI.

. 1996. Evolusi Tari Bali. Yogyakarta: Kanisisus. 
Brandon, James R. 2003. Jejak-Jejak Seni Pertunjukan di Asia Tenggara (penerjemah, Soedarsono). Bandung: P4S, Universitas Pendidikan Indonesia

Dibia, I Wayan. 1978. Pengantar Karawitan Bali. Denpasar: ASTI. . 1995. "Dari Wacak Ke Kocak sebuah Catatan Terhadap Perubahan Seni Pertunjukan Bali" dalam Mudra. Jurnal Seni Budaya No.3 Th.III Maret 1995. Denpasar: STSI.

Formagia, Maria Cristina. 2000. Gambuh Drama Tari Bali. Tinjauan Seni, Makna Emosional dan Mistik, Kata-Kata dan Teks. Musik Gambuh di Desa Batuan dan Desa Pedungan. Denpasar: Yayasan Lontar.

Haviland, William A. 1988. Antropologi Jilid II. Terjemahan R.G Sukardjito. Jakarta: Erlangga

Kayam, Umar. 2000. "Seni Pertunjukan Kita" Makalah sebagai Keynote Address Pertemuan MSPI 1999 di Tirtagangga , Bali 10 September 2000.

Pitana, I Gede. 1999. "Internasionalisasi dan Tradisionalisasi Pariwisata dan Dinamika Sosial Budaya Masyarakat Bali". Makalah disampaikan pada Matrikulasi Program Magister (S-2) Kajian Budaya Universitas Udayana tgl 20 Juli 1999.

Poespowardojo, Soejanto. 1993. Pembangunan Nasional dalam Persfektif Budaya. Jakarta: Grasindo.

Rota, I Ketut. 1977. "Persoalan Mula Pertama Adanya Gambuh di Bali". Laporan Penelitian. Denpasar: ASTI.

Said, Nur. 2000. "Pasang Surut Beberapa Kesenian Jawa Tradisional dalam Persfektif Globalisasi”, dalam Mudra, Jurnal Seni Budaya No.9 Th.VIII September 2000. Denpasar: STSI.

1999. Seni pertunjukan Indonesia dan Pariwisata. Bandung: Masyarakat Seni Pertunjukan Indonesia (MSPI)

Soedarsono. 1999. Seni Pertunjukan Indonesia dan Pariwisata. Bandung: Masyarakat Seni Pertunjukan Indonesia (MSPI).

Suartaya, I Kadek. 1994. "Gambuh Redup dalam Bingar PKB” dalam Wreta Cita No.2 Th.I Juni 1994. Denpasar: STSI

Sudana, I Wayan dkk. 1993. "Upaya Melestarikan Drama Tari Gambuh Pedungan". Laporan Penelitian. Denpasar: STSI.

Sudarsono, Juwono. 1992. Ilmu,Teknologi dan Etika berprofesi: Pandangan Sosial Politik dalam Masyarakat. Jakarta: Gramedia Pustaka Utama.

Sudiana, I Nyoman. 2000. " Pewarisan Gendhing-Gendhing Gambuh Masa Modernisasi (Studi Komparatif Terhadap Krisis Alih Generasi)". Laporan Penelitian.Denpasar: STSI.

Sumaatmaja, Nursid. 1998. Manusia dalam Konteks Susial Budaya dan Lingkungan Hidup. Bandung: Alfa Beta.

Supardan. 1991. Ilmu, Tekhnologi dan Etika. Jakarta: PT. BPK. Gunung Mulia. 
Wardizal. 2004. "Gamelan Gambuh: Tradisi yang Menyisih di Tengah Perkembangan Seni Karawitan di ISI Denpasar". Laporan Penelitian. Denpasar: ISI. 